Arq. Bras. Med. Vet. Zootec., v.67, n.4, p.1133-1140, 2015

\title{
Eficiência de genótipos de Brachiaria brizantha Stapf. (Syn: Urochloa brizantha) na produção de biomassa sob aplicação de fósforo
}

\author{
[Efficiency of genotypes of Brachiaria brizantha Stapf. (Syn: Urochloa brizantha) in biomass \\ production under phosphorus application] \\ M.A. Camacho $^{1}$, L.P.O. Silveira ${ }^{1 *}$, M.V. Silveira ${ }^{2}$ \\ ${ }^{1}$ Universidade Estadual de Mato Grosso do Sul - Aquidauana, MS \\ ${ }^{2}$ Universidade Federal de Viçosa - Viçosa, MG
}

\begin{abstract}
RESUMO
Este trabalho teve como objetivo avaliar a produção de biomassa e a eficiência agronômica em função do fornecimento de fósforo em diferentes genótipos de Brachiaria brizantha. O delineamento experimental utilizado foi inteiramente casualizado, em que os oito tratamentos consistiram em cinco variedades (Arapoty, Capiporã, Marandu, Piatã e Xaraés) e três acessos do banco de germoplasma do Centro Nacional de Pesquisa em Gado de Corte (B5, B10 e B12), em função da aplicação ou não de fósforo. As plantas foram cultivadas sob solo originalmente com $4,1 \mathrm{mg} \mathrm{dm}^{-3}$ de fósforo. Avaliou-se a massa seca da raiz (MSR), folha (MSF), parte aérea (MSPA) e a eficiência agronômica (EA). Os dados obtidos foram submetidos ao teste de Doon ao nível de 5\% de probabilidade. A produção de MSR foi incrementada pela aplicação de P nas variedades Arapoty, Capiporã, Piatã e Xaraés, em que os valores médios sem P foram de 5,$1 ; 7,4 ; 7,2$ e 5,8g vaso $^{-1}$, enquanto com aplicação de $\mathrm{P}$ foram de 9,4; 10,6; 11,9 e 8,4g vaso $^{-1}$, respectivamente. Para as variáveis MSF e MSPA, o P promoveu incremento da produção de todos os genótipos, produzindo em média 2,1 e $2,8 \mathrm{~g} \mathrm{vaso}^{-1}$, respectivamente, sem o fornecimento de $\mathrm{P}$, ao passo que, com o fornecimento de P, produziu 3,8 e 5,5g $\mathrm{vaso}^{-1}$, respectivamente, para MSF e MSPA. Os genótipos Arapoty e B5 foram os mais eficientes no uso de P. O genótipo B12 apresentou maior adaptação para cultivo em solos com baixas concentrações de $\mathrm{P}$, enquanto a variedade Arapoty sobressaiu-se quando realizada aplicação de adubo fosfatado. A variedade Arapoty e o genótipo B5 apresentaram maior eficiência no uso de $\mathrm{P}$, podendo-se indicar esses materiais para programas de melhoramento dessa espécie.
\end{abstract}

Palavras-chave: eficiência agronômica, forragicultura, nutrição de plantas

\begin{abstract}
This study aimed to evaluate biomass production and agronomic efficiency as a result of the supply of phosphorus in different genotypes of Brachiaria brizantha. The experimental design was completely randomized, with eight treatments consisting of five varieties (Arapoty, Capiporã, Marandu, and Piata Xaraés) and three accessions of the genebank of the Centro Nacional de Pesquisa em Gado de Corte (B5, $B 10$ and B12) with the application or not of phosphorus. The plants were grown in soil originally with 4.1 $m g \mathrm{dm}^{-3}$ phosphorus. We evaluated the root dry mass (MSR), leaf (MSF), shoot (MSPA) and agronomic efficiency (EA). Data were tested for Doon's at 5\% probability. MSR production was increased by the application of $P$ in Arapoty, Capiporã, and Piata Xaraés varieties, where the average values without phosphorus were 5.1, 7.4, 7.2 and 5.8g pot $^{-1}$ while with $P$ application they were 9.4, 10.6, 11.9 and $8.4 \mathrm{~g}$ pot $^{-1}$, respectively. For both variables MSF and MSPA, P promoted increased production of all genotypes, producing on average 2.1 and $2.8 \mathrm{~g} \mathrm{pot}^{-1}$ respectively, without the supply of $P$, whereas with the supply of $P$ it produced 3.8 and $5.5 \mathrm{~g} \mathrm{pot}^{-1}$, respectively for MSF and MSPA. Both genotypes Arapoty and B5 were the most efficient in the use of P. The B12 genotype showed greater adaptation for growing
\end{abstract}

Recebido em 15 de abril de 2013

Aceito em 16 de março de 2015

*Autor para correspondência (corresponding author)

E-mail: laura_bh_oliveira@hotmail.com 
in soils with low concentrations of $P$, while the Arapoty variety excelled when performed applying phosphate fertilizer. The genotypes B5 and Arapoty had higher P use efficiency, being able to indicate these materials for breeding programs of this species.

Keywords: agronomic efficiency, forage, plant nutrition

\section{INTRODUÇÃO}

A utilização de pastagem como fonte primária de alimento por bovinos é, sob o ponto de vista fisiológico desses animais, fundamental, tendo em vista que os ruminantes necessitam de fibra efetiva para se manterem saudáveis. O uso de pastagens na produção animal torna-se também mais atrativo sob o ponto de vista econômico, uma vez que não compete com produtos para a alimentação humana, o que ocorre no uso de alimentos concentrados, tornando-se uma fonte de alimento barato e, quando bem manejadas, oferecem os nutrientes necessários para o bom desenvolvimento dos animais (Marcelino et al., 2006).

A pecuária extensiva é uma das atividades mais importantes para a economia da região dos Cerrados, que, segundo dados do ANUALPEC (2011), estimados com base no Censo Agropecuário do IBGE, cerca de $44 \%$ do rebanho nacional bovino povoam essa região. Concomitantemente, os solos dessa região se caracterizam por serem altamente intemperizados e ácidos, e um dos principais fatores nutricionais limitantes para a produção nesses solos é a baixa disponibilidade de fósforo (P). O alto grau de intemperização dos solos do Cerrado gera altos teores de óxidos e sesquióxidos de ferro e alumínio, baixo $\mathrm{pH}$, altos teores de argilas silicatadas e baixo teor de matéria orgânica, que propiciam a adsorção de ânions, como o ortofosfato, diminuindo a disponibilidade de $\mathrm{P}$ (Novais et al., 2007). Essas características resultam em cerca de $80 \%$ das pastagens cultivadas nessa área apresentarem algum grau de degradação.

Segundo Oliveira et al. (2007), a baixa disponibilidade do $\mathrm{P}$ é um dos fatores mais restritivos para a pecuária, uma vez que as plantas forrageiras podem ser muito exigentes em $\mathrm{P}$, em virtude de uma maior produção de biomassa, consequente à maior extração e exportação desse nutriente.
Uma alternativa que vem sendo utilizada é o uso de gramíneas forrageiras tolerantes a baixas condições de fertilidade do solo. A seleção de materiais genéticos adaptados a condições de baixa fertilidade do solo aumenta o aproveitamento de fertilizantes aplicados, promovendo uma maior produção em solos de baixa fertilidade natural (Fernandes e Muraoka, 2002). Segundo Yan et al. (1995), a solução para elevar a produtividade e reduzir os custos de produção é a seleção de genótipos eficientes na utilização de nutrientes, que é definida, segundo Goedert e Lobato (1980), como a habilidade do genótipo em adquirir o nutriente do solo, incorporá-lo e utilizá-lo.

Nesse contexto, destacam-se as gramíneas do gênero Brachiaria, amplamente difundida nos sistemas pastoris brasileiros. Dentre essas forrageiras, a mais utilizada tem sido a $B$. brizantha, por apresentar um bom valor nutritivo, menor estacionalidade de produção, boa relação folha/haste, boa tolerância ao alumínio, boa tolerância a solos ácidos e relativa adaptação à baixa fertilidade (Paulino et al., 1994; Monteiro et al., 1995).

Segundo Marcelino et al. (2006), a capacidade de produção de uma pastagem está diretamente relacionada às condições ambientais às quais ela é submetida, bem como as práticas de manejo adotadas. Dessa forma, fatores como temperatura, luz, água e nutrientes condicionam o potencial fotossintético do dossel, resultando em alterações da área foliar e na capacidade fotossintética da planta. Sendo assim, as condições de ambiente e a baixa fertilidade do solo podem interferir na produção até mesmo das espécies mais adaptadas.

Nesse sentido, esse trabalho foi conduzido com o objetivo de avaliar a produção de biomassa e a eficiência agronômica em função do fornecimento de fósforo em diferentes genótipos de B. brizantha. 


\section{MATERIAL E MÉTODOS}

O trabalho foi conduzido em condições de casa de vegetação na Universidade Estadual de Mato Grosso do Sul (UEMS), campus de Aquidauana, com coordenadas geográficas $20^{\circ} 28^{\prime} \mathrm{S}, 55^{\circ} 40^{\prime}$ $\mathrm{W}$, numa altitude média de $207 \mathrm{~m}$ e pluviosidade anual média de $1.200 \mathrm{~mm}$, sendo o clima da região classificado como Aw, segundo a classificação de Köppen, com temperatura média anual de $26^{\circ} \mathrm{C}$. As amostras de um Argissolo Vermelho-Amarelo distrófico, textura média/argilosa, utilizadas neste experimento foram obtidas na camada de $0-20 \mathrm{~cm}$, apresentando as seguintes características: $\mathrm{pH}$ em água 5,6; P (Melich-1) 4,1 $\mathrm{mg} \mathrm{dm}^{-3} ; 0,15 ; 3,0$; 1,$4 ; 0,0 ; 1,8 \mathrm{cmol}_{\mathrm{c}} \mathrm{dm}^{-3}$, respectivamente, para $\mathrm{K}$, $\mathrm{Ca}, \mathrm{Mg}, \mathrm{Al}$ e $\mathrm{H}+\mathrm{Al}$; sendo a saturação por bases do solo equivalente a $72 \%$.

Após a coleta das amostras de solo, as mesmas foram secas e peneiradas (abertura de malha de $2 \mathrm{~mm}$ ), e depois acondicionadas em vasos com capacidade de $4 \mathrm{dm}^{3}$, com o interior revestido com sacos de polietileno para evitar a lixiviação de nutrientes. A semeadura foi realizada colocando-se cinco sementes por vaso e, sete dias após a emergência, realizou-se o desbaste, deixando duas plantas por vaso. Para suprir as necessidades hídricas da cultura, aplicou-se diariamente uma lâmina de 3,9mm de água. Os nutrientes, com exceção feita ao fósforo $(\mathrm{P})$, foram fornecidos via solução nutritiva apresentada em Oliveira et al. (1991).

O delineamento experimental utilizado foi o inteiramente casualizado, em um esquema fatorial $2 \times 8$, com quatro repetições. As fontes de variação foram a adubação (com e sem $\mathrm{P}$ ), os genótipos de Brachiaria brizantha (sendo cinco variedades comerciais (Marandu, Piatã, Capiporã, Xaraés, Arapoty) e três acessos do Banco de Germoplasma do Centro Nacional de Pesquisa de Gado de Corte da Embrapa (CNPGC/Embrapa), identificados como genótipos B5, B10 e B12. A adubação fosfatada (para os tratamentos com P) consistiu na aplicação de $1,2 \mathrm{~g}$ de $\mathrm{P}$ por vaso, via solução nutritiva, realizada em conformidade com o recomendado por Oliveira et al. (1991).

Após 70 dias de cultivo, as plantas foram cortadas rente ao solo, sendo coletadas a parte aérea e as raízes das plantas. A parte aérea da planta foi estratificada em folhas (limbo foliar) e colmo. Todas as amostras foram lavadas e secas em estufa de ventilação forçada a $65^{\circ} \mathrm{C}$ por $72 \mathrm{~h}$.

Os dados da colheita foram massa seca das raízes (MSR), folhas (MSF) e da parte aérea (MSPA). A eficiência agronômica (EA) foi calculada conforme relatado por Baligar et al. (2001), representada na equação abaixo:

EA $\left(\mathrm{g} \mathrm{g}^{-1}\right)=\frac{\text { Produção }(\text { com P), } \mathrm{g} \text { - Produção (sem P), g }}{\text { Quantidade de P aplicado, } \mathrm{g}}$

Após a análise inicial dos dados, os mesmos foram submetidos à análise de variância pelo teste de Kruscal-Wallis, e à comparação entre os genótipos realizada pelo teste de Doon ao nível de $5 \%$ de probabilidade.

\section{RESULTADOS}

A produção de fitomassa foi influenciada significativamente pelos fatores avaliados (aplicação de $\mathrm{P}$ e genótipos), bem como pela interação entre eles. Esse fato é importante, pois possibilita identificar genótipos com maior potencial produtivo em áreas com baixa disponibilidade de $\mathrm{P}$.

A produção de MSR foi incrementada pela aplicação de P nas variedades Arapoty, Capiporã, Piatã e Xaraés (Tab. 1), significando que a aplicação de $\mathrm{P}$ não aumentou a produção radicular na variedade Marandu e nos genótipos (B5, B10 e B12). As variedades Capiporã, Marandu e Piatã foram superiores aos genótipos estudados no presente trabalho quando submetidas à aplicação de $\mathrm{P}$, o que demonstra uma resposta positiva na produção de MSR frente à fertilização com esse nutriente.

Sem a aplicação de P, a variedade Marandu foi superior às variedades Xaraés e Arapoty e aos genótipos B5 e B10. O teor de P no solo foi considerado como baixo, segundo a classificação proposta por Lopes e Cox (1977), o que significa que as variedades Marandu, Capiporã e Piatã possuem equivalência em produção de MSR cultivados em solos com teores baixos de P, embora as variedades Capiporã e Piatã possam produzir mais frente à aplicação desse nutriente. Entretanto, a variedade Marandu foi a única, dentre as variedades comerciais, que não apresentou respostas de incremento na produção 
de raízes em função da aplicação de $\mathrm{P}$, indicando que, para essa característica, as variedades Arapoty, Capiporã, Piatã e Xaraés são mais responsivas à aplicação de $\mathrm{P}$ para produção de massa das raízes.

Tabela 1. Massa seca da raiz (MSR) em função da presença ou ausência de aplicação de $\mathrm{P}$ e incremento na produção $\left(\Delta_{\mathrm{MSR}}=\mathrm{MSR}_{\text {com } \mathrm{P}}-\right.$ $\mathrm{MSR}_{\text {sem P}}$ ) em genótipos de Brachiaria brizantha

\begin{tabular}{cccc}
\hline \multirow{2}{*}{ Genótipo } & \multicolumn{3}{c}{ MSR $(\mathrm{g})$} \\
\cline { 2 - 4 } & Com P & Sem P & $\Delta_{\text {MSR }}$ \\
\hline Arapoty & $9,4 \mathrm{ab}$ & $5,1 \mathrm{bc}$ & $4,3^{*}$ \\
Capiporã & $10,6 \mathrm{a}$ & $7,4 \mathrm{ab}$ & $3,2^{*}$ \\
Marandu & $11,2 \mathrm{a}$ & $9,1 \mathrm{a}$ & $2,1^{\mathrm{ns}}$ \\
Piatã & $11,9 \mathrm{a}$ & $7,2 \mathrm{abc}$ & $4,7^{*}$ \\
Xaraés & $8,4 \mathrm{ab}$ & $5,8 \mathrm{bc}$ & $2,6^{*}$ \\
B5 & $5,8 \mathrm{~b}$ & $5,5 \mathrm{bc}$ & $0,3^{\mathrm{ns}}$ \\
B10 & $6,6 \mathrm{~b}$ & $4,2 \mathrm{c}$ & $2,4^{\mathrm{ns}}$ \\
B12 & $6,1 \mathrm{~b}$ & $6,3 \mathrm{abc}$ & $0,2^{\mathrm{ns}}$ \\
\hline Média & 8,7 & 6,3 & - \\
CV & 29,3 & 33,9 & - \\
\hline
\end{tabular}

Médias seguidas pela mesma letra na coluna não diferem estatisticamente entre si pelo teste de Doon a $5 \%$ de probabilidade. $*=$ significativo a $5 \%$ de probabilidade pelo teste $\mathrm{F}$; ns = não significativo.

Para a variável MSF (Tab. 2), pode-se observar que o P promoveu diferença em todos os genótipos. Isso indica que o $\mathrm{P}$ está diretamente relacionado a uma maior produção de folhas e, consequentemente, uma maior qualidade de forrageira. A variedade Arapoty obteve maior produção de MSF no tratamento que recebeu adição de $\mathrm{P}$ quando em comparação com os genótipos Capiporã, Xaraés, B10 e B12. O bom desempenho produtivo do genótipo Arapoty em ambos os tratamentos estudados para a produção de folhas indica que este possui boa capacidade de produção, tanto em solos com quantidades satisfatórias de $\mathrm{P}$ quanto em solos com baixos teores desse nutriente. No entanto, a produção da variedade Arapoty aumenta (109\%) quando é disponibilizado $\mathrm{P}$, o que indica que se podem obter resultados ainda mais satisfatórios desse genótipo quando se realiza a adubação fosfatada.

Por outro lado, o genótipo B12 não se destacou dentre os que mais produziram no tratamento que recebeu $\mathrm{P}$, mas se destacou dentro do tratamento que não recebeu adição desse nutriente. Esse comportamento pode indicar que esse genótipo produz plantas rústicas e adaptadas a solos de baixa fertilidade e que, embora não tenha uma produção comparada a outras variedades de $B$. brizantha, se tornam uma alternativa em solos com deficiência desse nutriente. No entanto, mais pesquisas necessitam ser feitas nesse sentido, para que se avalie a real adaptação desse genótipo a ambientes com baixa disponibilidade de P.

Tabela 2. Massa seca da folha (MSF) em função da presença ou ausência de aplicação de $\mathrm{P}$ e incremento da produção $\left(\Delta_{\mathrm{MSF}}=\mathrm{MSF}_{\text {com } \mathrm{P}}-\right.$ $\mathrm{MSF}_{\text {sem P}}$ ) em genótipos de Brachiaria brizantha

\begin{tabular}{cccc}
\hline \multirow{2}{*}{ Genótipo } & \multicolumn{3}{c}{ MSF $(\mathrm{g})$} \\
\cline { 2 - 4 } & Com P & Sem P & $\Delta_{\text {MSF }}$ \\
\hline Arapoty & $4,8 \mathrm{a}$ & $2,3 \mathrm{ab}$ & $2,5^{*}$ \\
Capiporã & $2,8 \mathrm{c}$ & $1,6 \mathrm{c}$ & $1,2^{*}$ \\
Marandu & $4,0 \mathrm{ab}$ & $2,0 \mathrm{bc}$ & $2,0^{*}$ \\
Piatã & $4,3 \mathrm{ab}$ & $2,3 \mathrm{ab}$ & $2,0^{*}$ \\
Xaraés & $3,6 \mathrm{bc}$ & $1,9 \mathrm{bc}$ & $1,7^{*}$ \\
B5 & $4,1 \mathrm{ab}$ & $2,1 \mathrm{abc}$ & $2,0^{*}$ \\
B10 & $3,4 \mathrm{bc}$ & $1,6 \mathrm{c}$ & $1,8^{*}$ \\
B12 & $3,8 \mathrm{bc}$ & $2,7 \mathrm{a}$ & $1,1^{*}$ \\
\hline Média & 3,8 & 2,1 & - \\
CV & 17,5 & 20,2 & - \\
\hline
\end{tabular}

Médias seguidas pela mesma letra na coluna não diferem estatisticamente entre si pelo teste de Doon a $5 \%$ de probabilidade. $*=$ significativo a $5 \%$ de probabilidade pelo teste $\mathrm{F} ; \mathrm{ns}=$ não significativo.

Pode-se observar que o $\mathrm{P}$ promoveu $\mathrm{O}$ incremento da produção de MSPA para todos os genótipos (Tab. 3), concordando com os resultados anteriormente descritos, em que a adubação fosfatada promove aumento na produção de biomassa de folhas. Para o tratamento com aplicação de $\mathrm{P}$, as variedades Arapoty, Piatã e o genótipo B5 obtiveram as maiores médias, juntamente com os demais, diferindo significativamente apenas da variedade Capiporã.

Para o tratamento sem P, o genótipo B12 obteve a maior média, não diferindo apenas do genótipo Piatã. Os dados obtidos em MSPA para o genótipo B12 são semelhantes aos obtidos em MSF, pois este obteve produção elevada em situação de baixa disponibilidade de P, quando comparado aos demais. Mais estudos precisam ser feitos; no entanto, este trabalho pode inferir a utilização desse genótipo para ser cultivado em solos deficientes em $\mathrm{P}$. 
Tabela 3. Massa seca da parte aérea (MSPA) em função da presença ou ausência de aplicação de $\mathrm{P}$ e incremento da produção $\left(\Delta_{\mathrm{MSPA}}=\mathrm{MSPA}_{\mathrm{com} \mathrm{P}}-\right.$ $\mathrm{MSPA}_{\mathrm{sem}}{ }_{\mathrm{P}}$ ) em genótipos de Brachiaria brizantha

\begin{tabular}{cccc}
\hline \multirow{2}{*}{ Genótipo } & \multicolumn{3}{c}{ MSPA } \\
\cline { 2 - 4 } & Com P & Sem P & $\Delta_{\text {MSPA }}$ \\
\hline Arapoty & $6,6 \mathrm{a}$ & $2,9 \mathrm{~b}$ & $3,7^{*}$ \\
Capiporã & $4,0 \mathrm{~b}$ & $2,4 \mathrm{~b}$ & $1,6^{*}$ \\
Marandu & $5,3 \mathrm{ab}$ & $2,5 \mathrm{~b}$ & $2,8^{*}$ \\
Piatã & $5,7 \mathrm{a}$ & $3,1 \mathrm{ab}$ & $2,6^{*}$ \\
Xaraés & $5,4 \mathrm{ab}$ & $2,5 \mathrm{~b}$ & $2,9^{*}$ \\
B5 & $6,3 \mathrm{a}$ & $2,9 \mathrm{~b}$ & $3,4^{*}$ \\
B10 & $5,3 \mathrm{ab}$ & $2,4 \mathrm{~b}$ & $2,9^{*}$ \\
B12 & $5,4 \mathrm{ab}$ & $3,8 \mathrm{a}$ & $1,6^{*}$ \\
\hline Média & 5,5 & 2,8 & - \\
CV & 18,3 & 19,4 & - \\
\hline
\end{tabular}

Médias seguidas pela mesma letra na coluna não diferem estatisticamente entre si pelo teste de Doon a $5 \%$ de probabilidade. $*=$ significativo a $5 \%$ de probabilidade pelo teste $\mathrm{F}$; ns = não significativo.

A eficiência agronômica dos genótipos de Brachiaria brizantha demonstrou diferença varietal (Fig. 1). A eficiência agronômica diz respeito ao quanto a planta consegue produzir a mais de biomassa para cada unidade de $\mathrm{P}$ aplicada, mensurando a capacidade e eficiência da planta em utilizar o P do solo. Observa-se que os genótipos Arapoty e B5 foram os mais eficientes no uso de $\mathrm{P}$, ou seja, produziram mais biomassa na parte aérea por unidade de $\mathrm{P}$ aplicada, enquanto a variedade Capiporã e o genótipo B12 foram menos eficientes.

\section{DISCUSSÃO}

O P incrementou, de um modo geral, a produção de biomassa de todos os genótipos avaliados, confirmando os dados da literatura que ressaltam sua importância na produção forrageira. No entanto, para massa seca de raízes, não houve diferença à adição de $\mathrm{P}$ para os genótipos Marandu, B5, B10 e B12. Ao Marandu, pode-se atribuir o fato de possuir uma elevada capacidade de desenvolvimento do sistema radicular e sua adaptação a situações de baixa fertilidade dos solos. Para os demais genótipos, outros estudos necessitam ser realizados.

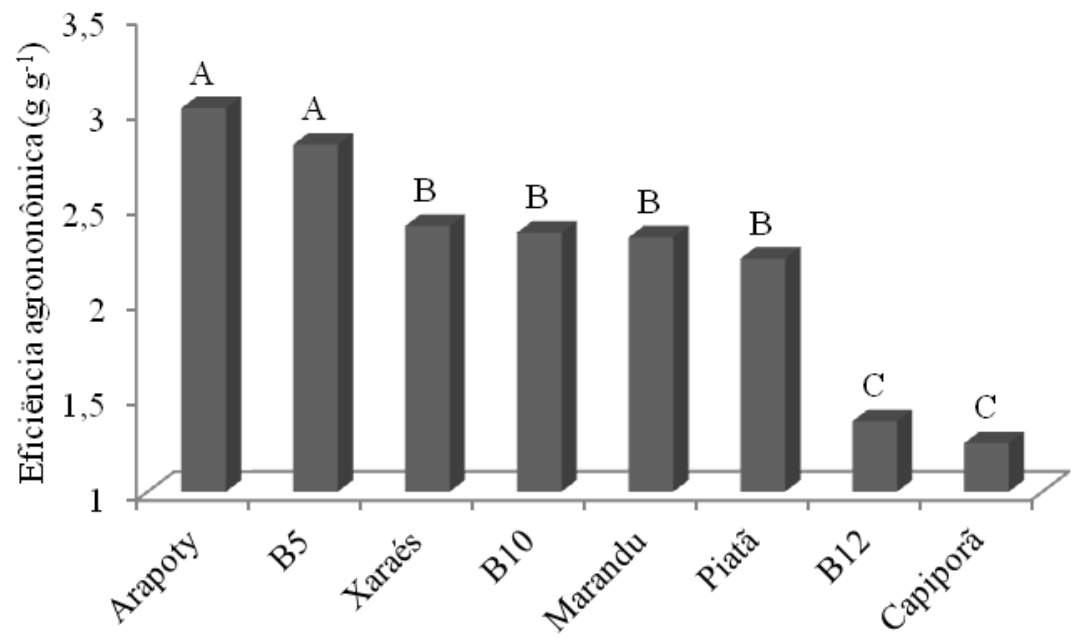

Figura 1. Eficiência agronômica no aproveitamento de $\mathrm{P}$ dos genótipos de Brachiaria brizantha avaliados.

O fato de a variedade Marandu apresentar um grande desenvolvimento radicular e uma baixa produção de parte aérea, em comparação com os demais genótipos, confirma os dados de Rao et al. (1996), pois o crescimento de raízes é menos limitado na condição de baixa disponibilidade de $\mathrm{P}$ do que a parte aérea da planta, enquanto Mesquita et al. (2004) verificaram que a aplicação de doses crescentes de $\mathrm{P}$ favoreceram mais a produção de parte aérea que a de raízes.

O P tem grande efeito sobre a produção de raízes das plantas, principalmente na fase de estabelecimento, por isso é recomendado que a adubação fosfatada seja realizada na ocasião da implantação da pastagem (Raij et al., 1997), 
principalmente nos sistemas intensivos de produção (Moreira et al., 2006), auxiliando o perfilhamento dessas plantas.

$\mathrm{Na}$ produção de parte aérea, houve resposta significativa à adição de $\mathrm{P}$ para todos os genótipos. Estes resultados confirmam os encontrados por Rossi e Monteiro (1999), que avaliaram a produção de massa seca dos capins Brachiaria e Panicum em função do fornecimento desse nutriente.

Os tratamentos que receberam adição de $\mathrm{P}$ tiveram maiores produções de biomassa, tanto de folhas quanto de parte aérea, e respostas significativas à adição desse nutriente em comparação com os tratamentos que não receberam P. Em concordância, Monteiro et al. (1995) descrevem que as plantas oriundas dos tratamentos com omissão de $\mathrm{P}$ tiveram seu crescimento limitado e, consequentemente, uma baixa produção de matéria seca, principalmente de parte aérea, permanecendo raquíticas e sem perfilhos. Segundo Santos et al. (2009), a produtividade de uma gramínea decorre da sua contínua capacidade de emissão de folhas e perfilhos, o que se torna um processo importante após o corte ou pastejo para restaurar a área foliar da planta e permitir a perenidade do pasto.

Em concordância com os autores acima citados, Corrêa e Haag (1993) avaliaram níveis críticos de P no cultivo de Brachiaria spp., relatando que as espécies de gramíneas obtiveram massa seca de parte aérea considerável em presença de $\mathrm{P}$ e declive acentuado de produção nos tratamentos com privação desse nutriente. No presente experimento, a adição de $\mathrm{P}$ foi significativa para todos os genótipos, confirmando os resultados encontrados pelos autores. Pode-se observar que a adubação fosfatada é uma prática viável, pois as plantas respondem significativamente à adição de $\mathrm{P}$, através do aumento da produção de biomassa foliar. Embora havendo semelhança entre as produções dos genótipos, o genótipo Arapoty apresentou os resultados mais satisfatórios, em todas as variáveis estudadas.

Com metodologia diferente da utilizada neste trabalho, Machado e Valle (2011) realizaram experimento testando a produtividade de seis variedades de $B$. brizantha (Marandu, MG4, Xaraés, Piatã, Arapoty e B6), não levando em consideração o fornecimento de $\mathrm{P}$, mas a sucessão à soja. Os resultados demonstram que a variedade Xaraés obteve as melhores produções, inclusive a de folhas, diferindo dos resultados obtidos neste experimento. No entanto, os autores mostram que a variedade Arapoty tem a menor produção de colmos quando comparada às demais variedades, e uma relação folha:colmo que não diferiu da variedade Xaraés (mais produtiva), reforçando a recomendação da variedade Arapoty.

O comportamento do genótipo B12, ao apresentar uma maior produção de folhas e de parte aérea no tratamento que não recebeu adição de $\mathrm{P}$, pode indicar uma melhor adaptação desse genótipo a solos de baixa fertilidade. Mais estudos necessitam ser realizados nesse sentido; no entanto, esse genótipo pode vir a ser uma opção para o cultivo de plantas forrageiras em situações em que a deficiência do solo limita a produção de espécies mais exigentes.

Os resultados da resposta ao $\mathrm{P}$ pelo genótipo Arapoty indicam uma maior eficiência agronômica (EA) desse genótipo em relação às outras variedades avaliadas. Entende-se por EA a capacidade da planta em retirar o $\mathrm{P}$ do solo e utilizá-lo para o crescimento. Segundo Ramos et al. (1997), o aumento da produção de forragem em solos ácidos e de baixa fertilidade dos trópicos é possível através do uso de fertilizantes fosfatados em quantidades adequadas e a utilização de plantas adaptadas às características edafoclimáticas do local, que usem eficientemente o $\mathrm{P}$ aplicado.

Segundo Santos et al. (2006), a eficiência agronômica, bem como a facilidade de absorção de $\mathrm{P}$ pelas plantas, está relacionada a fatores ligados ao solo e à própria planta. A exigência metabólica de cada genótipo é um fator fundamental. Assim, como os genótipos avaliados neste experimento foram cultivados em um solo com as mesmas características químicas, as diferenças encontradas entre as mesmas, quanto à eficiência de absorção, foram decorrentes da exigência metabólica de cada genótipo. Mais estudos devem ser feitos nesse sentido, para que se determinem espécies e genótipos dentro de cada espécie com maior potencial produtivo e que sejam capazes de aproveitar melhor os nutrientes disponíveis no solo; sugere-se, no entanto, a utilização dos 
materiais mais eficientes para a obtenção de novas linhagens e variedades.

\section{CONCLUSÕES}

A aplicação de $\mathrm{P}$ melhora a produção de massa seca em $B$. brizantha, sobressaindo-se a parte área comparativamente às raízes. O genótipo B12 apresentou maior adaptação para cultivo em solos com baixas concentrações de $\mathrm{P}$, enquanto a variedade Arapoty sobressaiu-se quando realizada aplicação de adubo fosfatado. A variedade Arapoty e o genótipo B5 apresentaram maior eficiência agronômica da aplicação de P, podendo-se indicar esses materiais para programas de melhoramento dessa espécie.

\section{AGRADECIMENTOS}

À Dra. Cacilda Borges do Valle, da Embrapa Gado de Corte, pela cedência do germoplasma.

\section{REFERÊNCIAS}

ANUALPEC. Anuário da pecuária brasileira. São Paulo: Instituto FNP, 2011. p.378.

BALIGAR, V.C.; FAGERIA, N.K.; HE, Z.L. Nutrient use efficiency in plants. Comm. Soil Sci. Plant Anal., v.32, p.921-950, 2001.

CORRÊA, L.A.; HAAG, H.P. Disponibilidade de fósforo pelos extratores de mehlich 1 e resina em latossolo vermelho amarelo, álico cultivado com três gramíneas forrageiras. Sci. Agric., v.50, p.287-294, 1993.

FERNANDES, C.; MURAOKA, T. Absorção de Fósforo por Híbridos de milho cultivados em solo de Cerrado. Sci. Agric., v.59, p.781-787, 2002.

GOEDERT, W.J.; LOBATO, E. Eficiência agronômica de fosfatos em solos de cerrado. Pesq. Agropec. Bras., v.15, p.311-318, 1980.

LOPES, A.S.; COX, F.R. A survey of the fertility status of surface soils under "cerrado" vegetation in Brazil. Soil Sci. Soc. Am. J., v.41, p.742-747, 1977.

MACHADO, L.A.Z.; VALLE, C.B. Desempenho agronômico de genótipos de capim-braquiária em sucessão à soja. Pesq. Agropec. Bras., v.46, p.1454-1462, 2011.
MARCELINO, K.R.A.; NASCIMENTO JUNIOR, D.; SILVA, S.C. et al. Características morfogênicas e estruturais e produção de forragem do capim Marandú submetido à intensidade e frequência de desfolhação. Rev. Bras. Zootec., v.35, p.2243-2252, 2006.

MESQUITA, E.E.; PINTO, J.C.; FURTINI NETO, A.E. et al. Teores críticos de fósforo em três solos para o estabelecimento de capimmombaça, capim-marandu e capim-andropogon em vasos. Rev. Bras. Zootec., v.33, p.290-301, 2004.

MONTEIRO, F.A.; RAMOS, A.K.B.; CARVALHO, D.D. et al. Cultivo de Brachiaria brizantha Stapf. cv. Marandú em solução nutritiva com omissão de macronutrientes. Sci. Agric., v.52, p.135-141, 1995.

MOREIRA, L.M.; FONSCECA, D.M.; MARTUSCELLO, J.A. et al. Absorção e níveis críticos de fósforo na parte aérea para manutenção da produtividade do Capim-Elefante (Pennisetum purpureum cv. Napier). Ciênc. Agrotec., v.30, p.1170-1176, 2006.

NOVAIS, R.F.; SMYTH, T.J.; NUNES, F.N. Fósforo. In: NOVAIS, R.F.; ALVAREZ, V.H.; BARROS, N.F. et al. Fertilidade do Solo. Viçosa: Sociedade Brasileira de Ciências do Solo, 2007. p.471-550.

OLIVEIRA, A.J. Métodos de pesquisa em fertilidade do solo. Brasília: EMBRAPA-SEA, 1991. 232p.

OLIVEIRA, P.P.A.; OLIVEIRA, W.S.; CORSI, M. Efeito residual de fertilizantes fosfatados solúveis na recuperação de pastagem de Brachiaria brizantha cv. Marandú em Neossolo Quartzarênico. Rev. Bras. Zootec., v.36, p.17151728, 2007.

PAULINO, V.T.; COSTA, N.L.; LUCENA, M.A.C. et al. Resposta de Brachiaria brizantha cv. Marandú a calagem e a fertilização fosfatada de um solo ácido. Pasturas Tropicales, v.16, p.34-40, 1994.

RAIJ. B.; CANTARELLA. H.; QUAGGIO, J.A. et al. Recomendações de adubação e calagem para o estado de São Paulo. 2.ed. Campinas: Instituto Agronômico/Fundação IAC, 1997. 285 p. 
RAMOS, G.M.; ITALIANO, E.C.; LEITE, G.G. et al. Doses de fósforo na produção de gramíneas forrageiras em solos ácidos e de baixa fertilidade na região meio norte do Brasil. Pasturas Tropicales, v.19, p.24-27, 1997.

RAO, I.M.; BORRERO, V.; RICAURTE, J. et al. Adaptive attributes of tropical forage species to acid soils: 2. Differences in shoot and root growth responses to varying phosphorus supply and soil type. J. Plant Nutr., v.19, p.323-352, 1996.

ROSSI, C.; MONTEIRO, F.A. Doses de fósforo, épocas de coleta e o crescimento e diagnose nutricional nos capins braquiária e colonião. Sci. Agric., v.56, p.1101-1110, 1999.
SANTOS, I.P.A.; PINTO, J.C; FURTINI NETO, A.E. et al. Frações de fósforo em gramíneas forrageiras tropicais sob fontes e doses de fósforo. Cienc. Agrotec., v.30, p.961-970, 2006.

SANTOS, L.C.; BONOMO, P.; SILVA, V.B. et al. Características morfogênicas de braquiárias em resposta a diferentes adubações. Acta Sci. Agron., v.31, p.221-226, 2009.

YAN, X; LYNACH, J.P; BEEBE, S.E. Genetic variation for phosphorus efficiency of common bean in contrasting soil types. I. Vegetative response. Crop Sci., v.35, p.1086-1093, 1995. 